
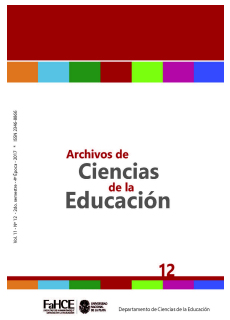

Archivos de Ciencias de la Educación, Vol 11, nº 12, diciembre 2017, e035. ISSN 2346-8866

Universidad Nacional de La Plata.

Facultad de Humanidades y Ciencias de la Educación.

Departamento de Ciencias de la Educación.

\title{
"Lo que el borrador no se llevó". Una exhibición sobre la historia de la educación en Argentina
}

\section{Daniela Carnevalini}

Universidad Nacional de La Plata, Argentina | dani cne@hotmail.com

"Lo que el borrador no se llevó" es una muestra itinerante e interactiva del Museo de las Escuelas, creado en el año 2002, de manera conjunta, por el Ministerio de Educación de la Ciudad de Buenos Aires y la Universidad Nacional de Luján. El museo fue inaugurado en el año 2002 y se plantea como objetivo general que la comunidad escolar, alumnos/as, familias y vecinos puedan pensar la escuela como una construcción social e imaginarse como constructores de la educación del futuro.

El foco del museo son los visitantes y los encuentros intergeneracionales que se generan entre ideas, objetos, prácticas del mundo de las infancias y la educación (Alderoqui, 2012). Los/as visitantes son invitados/as a desnaturalizar la escuela que conocen, a leerla y re-pensarla, generando preguntas sobre discursos y prácticas escolares y aquellos que aún perduran. Las imágenes, interrogantes y los objetos exhibidos en los paneles, son los que colaboran para que esto sea posible.

La exhibición aborda los orígenes de la escuela Argentina entre 1580 y 1976, ofreciendo claves de lectura en sus imágenes que ayudan a comprender su génesis, la variedad de discursos y prácticas escolares, sus rupturas y continuidades. Se compone de 14 paneles colgantes de lona vinílica, con diversos títulos y enumerados para su colocación. Pueden disponerse en espacios de usos colectivos (pasillos, galería, patio cubierto, salón de usos múltiples, etc.), modificando por unos días o semanas el espacio de lo cotidiano y generando un lugar para el encuentro, el disfrute, la reflexión, a través de la conversación, y el dialogo, ofreciendo la posibilidad de detenerse, sentir e imaginar.

La exhibición es itinerante y está destinada a diversas instituciones educativas y culturales. Está acompañada 
por un cuadernillo $\underline{1}$ diseñado por el equipo educativo del Museo de las Escuelas, con sugerencias y actividades para recorrer la exhibición de manera individual o grupal, como parte de un paseo a paso lento o sobrevolando por cada panel. Proponiendo diversidad de recorridos posibles para aquellos que la solicitan.

Uno de los itinerarios que ofrece el cuadernillo es el denominado panel por panel, en cada uno de ellos se aborda una temática referida a la educación en Argentina. A continuación, me detendré en algunos de ellos: el panel 2 "Letra con sangre. Una enseñanza desigual" interroga a los visitantes sobre la educación en la época de la colonia entre 1580 y 1810. La imagen que se exhibe es una acuarela de Emeric Essex Vidal a la salida de la iglesia de Santo Domingo, e invita a los visitantes a buscar pistas, inquietarse y pensar sobre las desigualdades y los derechos en la educación.

Mientras que los paneles 4 y 5 "Una sola patria. La enseñanza común” (desde 1870) recupera la inmigración del siglo XX y la enseñanza impartida en el territorio argentino, una educación común de formación ciudadana. La consolidación del Estado y la formación del Sistema Educativo Nacional con la sanción de la ley 1.420.

Por otro lado, el panel 9 “Construir argentinos. Formación de la nacionalidad” se exponen algunos de los libros de lectura, geografía e instrucción cívica que circulaban en las escuelas con la intención de desarrollar actitudes de pertenencia a la nación Argentina. También se detiene en los cambios en los libros de lectura entre 1880 y 1940.

El panel 12 “Primero al jardín! El juego educa” (desde 1870) propone volver la mirada al Jardín de Infantes, deteniéndose en los cambios o continuidades en los espacios de juego y en los delantales. Una pregunta al final del panel invita a desnaturalizar la escuela: ¿Qué tiene de jardín el jardín de infantes?

Finalizando el panel 14 “Anticipaciones por la educación del futuro." plantea un juego de afirmación y pregunta, pregunta y respuesta que deja al visitante con más dudas que certezas y propone un mensaje alentador invitando pensar e imaginar la escuela que vendrá.

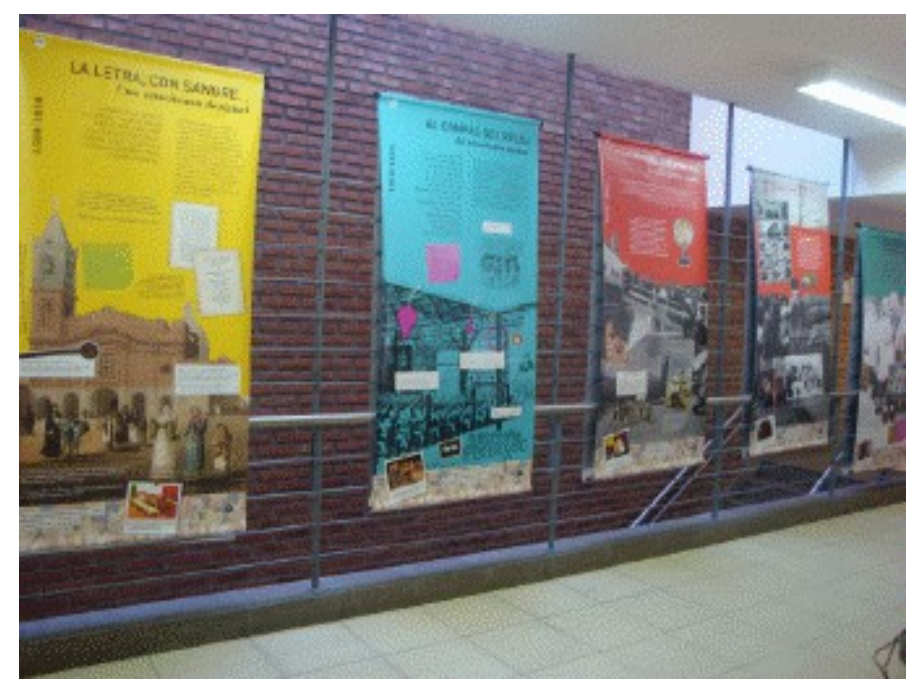

Paneles de la muestra durante la conmemoración de los 125 años de la Escuela N² de 3 "Fray Cayetano Rodríguez”. Ciudad Autónoma de Buenos Aires, noviembre de 2012.

Otro de los itinerarios posibles es el temático: Construcción de la patria (Paneles: 4, 5, 6, 7, 9, 11); Mobiliario y útiles escolares (Paneles: 2, 3, 6, 7, 8, 9, 10, 11); Aulas y espacios de la escuela (Paneles: 2, 7, 8, 11, 12, 13); Alfabetización y libros de lectura (Paneles: 2, 3, 7, 9,10); Igualdad-desigualdad (económica, social, de género) (Paneles: 2, 4, 3, 5, 6, 7, 9, 12); Los docentes y la pedagogía (Paneles: 3, 5, 7, 8, 12 ); Premios y castigos (Paneles: 2, 3, 5, 6, 7, 8, 9, 10, 13). 
El itinerario enigmático es otro de los recorridos que se sugiere en el cuadernillo. Consta de una hoja con actividades, en donde el visitante se enfrenta a diversos desafíos a resolver. Para ello deberá recorrer la muestra “jugando a ser detective”, buscando pistas y resolviendo enigmas.

Finalmente, otra posibilidad de recorrer la exhibición es "el plegadizo", en donde se entrega al visitante una hoja impresa con el "juego del sapito" para armar. El mismo contiene preguntas que deberá ir resolviendo con ayuda de los paneles, focalizando en los juegos de ahora y de otros tiempos. Ambas hojas pueden imprimirse y repartirse a los visitantes.

El Museo de las Escuelas se inscribe dentro de una museología crítica, que concibe tanto la narrativa de los visitantes como las del objeto y donde los educadores de museos ocupan un lugar central en la organización de actividades, diseño, montaje y evaluación de las exposiciones. (Alderoqui y Pedersoli, 2011).

Recién cuando en un museo se plantean los problemas de cómo los visitantes eligen su herencia y deja de pensarse en primer término en las colecciones; cuando se pasa de un énfasis taxonómico a un énfasis explicativo, que acepta las ambigüedades y contradicciones, y comienza a intervenir el pensamiento cuestionador y crítico acerca del lugar que ocupan las voces del público como fuente de conocimiento en el desarrollo de las exposiciones, es cuando su función educativa comienza a tener cierto espesor (Alderoqui y Pedersoli, 2011).

La propuesta educativa del Museo de las Escuelas, como plantean (Alderoqui y Pedersoli, 2011), se centra en las experiencias lúdicas, emocionales y cognitivas de sus visitantes, poniendo en juego sus percepciones, afectos, imaginarios e ideas. Recuperar las voces de los visitantes y considerarlos partícipes de la historia social de la educación y, por consiguiente, recuperar sus relatos, diálogos, sensaciones, emociones y anécdotas, los convierte en parte del patrimonio y de la exposición.

Como se intentó trasmitir en esta reseña, la exhibición “Lo que el borrador no se llevó” presenta un amplio recorrido, con un sustento teórico que la constituye, poniendo al visitante en el centro de la escena como artífice de experiencias y prácticas, y con una diversidad de temáticas sobre la educación argentina abordadas en cada panel.

Hemos llegado al final del recorrido, el cual invito a transitar para inaugurar nuevas voces, experiencias y diálogos en la exhibición. ¿Cómo solicitarla? Por aquí podrán requerirla: museodelasescuelas@bue.edu.ar.

\section{Notas}

1 Documento disponible en el sitio web del Museo de las escuelas: http://www.buenosaires.gob.ar/sites/gcaba/files/ideasloqueelborradornosellevo.pdf

\section{Bibliografía}

Alderoqui, S. y Pedersoli, C. (2011). Desvelados por los visitantes. En La educación en los museos. De los objetos a los visitantes. Buenos Aires: Editorial Paidós.

Alderoqui, S.; Linares M. C; Fisman, D.; Pedersoli, C.; Pugliese, M.; Holstein, A.; Caride, J. (2012). Curadurías en conversación. Los visitantes como patrimonio. El museo de las escuelas. (9-10). Buenos Aires. 